\title{
Sizing Energy Storage on the 11kV Distribution Network
}

\author{
D Strickland, X Bai \\ School of Engineering and Applied Science, Aston University, Birmingham, B4 7ET
}

Keywords: Energy storage, capacity fade, battery lifecycle, peak load lopping

\begin{abstract}
The cost and limited flexibility of traditional approaches to $11 \mathrm{kV}$ network reinforcement threatens to constrain the uptake of low carbon technologies. Ofgem has released $£ 500 \mathrm{~m}$ of funding for DNOs to trial innovative techniques and share the learning with the rest of the industry. One of the techniques under study is the addition of Energy Storage at key substations to the network to help with peak load lopping. This paper looks in detail at the sizing algorithm for use in the assessment of alternatives to traditional reinforcement and investigates a method of sizing a battery for use on a Network taking into account load growth, capacity fade and battery lifecycle issues. A further complication to the analysis is the method of operation of the battery system and how this affects the Depth of Discharge (DoD). The proposed method is being trialled on an area of $11 \mathrm{kV}$ network in Milton Keynes Central area and the simulation results are presented in this paper.
\end{abstract}

\section{Introduction}

To enable Distribution Network Operators (DNOs) to develop new approaches to reinforce the $11 \mathrm{kV}$ network with low carbon technologies, Ofgem has released $£ 500 \mathrm{~m}$ of funding for DNOs to trial innovative techniques and share the learning with the rest of the industry. Project FALCON (Flexible Approaches to Low Carbon Optimised Networks) is funded via this Ofgem initiative, and aims to facilitate the uptake of low carbon technologies by delivering faster and cheaper connections to the $11 \mathrm{kV}$ network by reducing traditional reinforcement requirements. The trial will provide learning on the use of real time data to inform network planning rather than traditional indicators such as total demand and engineering guidelines. The learning obtained throughout the project will be shared with other DNOs and the wider industry.

Energy Storage at key substations is one such technique being studied to help with peak load shaving. Within literature there are a number of methodologies used to size and place battery energy storage systems around the grid. The majority of these studies are either concerned with wind farm generation for both grid and non-grid connected systems [1,2] or with micro grids [3,4] and only a small number look into sizing and costing of systems for offsetting grid reinforcement costs [5]. The published work is split into a combination of theoretical studies only and those with minimal life cycle validation on a microgrid. In some cases, the authors take into account battery life cycle but ignore capacity fade [3] and in others both capacity fade and life cycle are ignored [5]. Other documentation in this research arena concentrates on the control (switching energy storage in and out) and assumes the energy storage size has already been adequately set [6].

Firstly, a method of sizing a battery is investigated for use on a Network taking into account load growth, capacity fade and battery lifecycle issues using a battery equivalent circuit model. Finally, the paper uses a case study example from the FALCON trials to indicate how future sizing and implementation of energy storage could impact life cycle, using load profiles at different substations around the trial network taken from measured data.

\section{Battery sizing algorithm}

To use a battery as an alternative to Network reinforcement requires that the power and energy needed to displace the reinforcement be known. From Network modelling, the load curve can be run and the minimum power and energy requirement of the battery can be established from the yellow area as shown in Figure 1

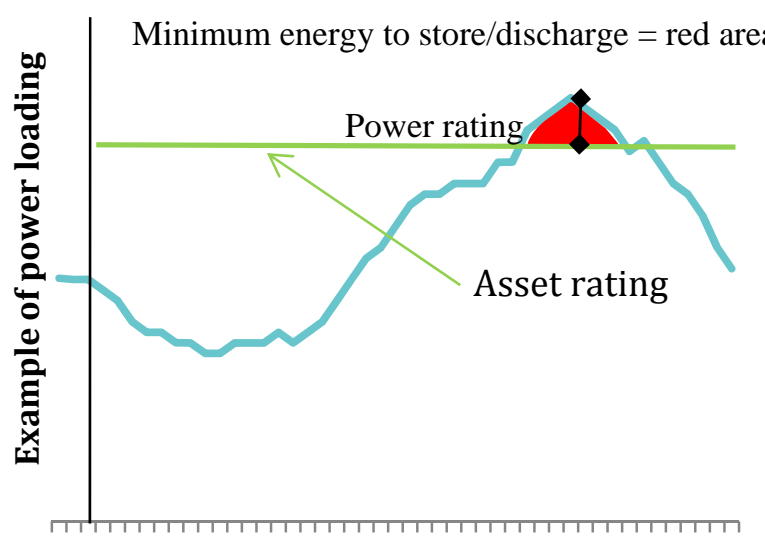

14710131619222528313437404346

$1 / 2$ hour period

Fig 1: Minimum battery sizing

However, the battery cannot just be sized on minimum energy and power rating reduction from Figure 1, because battery life cycle is highly dependent on depth of discharge. A full battery discharge $(100 \%)$ daily over a period of years will reduce the life cycle significantly. For example, a lead acid 
battery operating daily to full discharge would be unlikely to last past 2 years of operation. Unfortunately, as a battery is deployed within an electricity network its capacity will fade with time - so as the yearly load goes up there is reduced energy available to meet demand and the battery life span will degrade quicker as the depth of discharge increases.

To compensate for this a load growth factor $\left(\mathrm{F}_{\mathrm{LG}}\right)$, life span factor $\left(\mathrm{F}_{\mathrm{LS}}\right)$ and capacity factor $\left(\mathrm{F}_{\mathrm{CF}}\right)$ have been suggested as means of sizing the battery to compensate for loss of life and capacity fade under load growth scenarios as shown in Figure 2. The life span of the battery is also affected by thermal temperature. However, the accuracy, with, which this can be included versus the level of confidence in the results suggests that considering this to be negligible at this time is the most appropriate way forward [7-9]. It is possible to include at a later date but does require detailed information on battery construction and thermal constants. An additional assumption is that the battery leakage (from sitting around doing nothing) is also negligible, but may be included within an efficiency factor if required.

\begin{tabular}{|c|c|}
\hline $\begin{array}{c}\text { Determine the } \\
\text { required power } \\
\left(\mathrm{P}_{\mathrm{b}}\right) \text { and energy } \\
\left(\mathrm{E}_{\mathrm{b}}\right) \text { to resolve } \\
\text { the issue } \\
\text { (Figure 1) }\end{array}$ & $\rightarrow \begin{array}{l}\text { Apply a factor for } \\
\text { 1) Load growth } \\
\text { 2) Sensitivity for } \\
\text { meshed } \\
\text { 3) Capacity fade } \\
\text { of battery } \\
\text { 4) Meeting } \\
\text { minimum life } \\
\text { span }\end{array}$ \\
\hline $\begin{array}{l}\text { Set a minimum } \\
\text { life span }\end{array}$
\end{tabular}

Fig 2: Battery sizing specification

The process for determining the battery size from the power $\left(\mathrm{P}_{\mathrm{b}}\right)$ and energy $\left(\mathrm{E}_{\mathrm{b}}\right)$ needed to meet the asset rating limits are as follows;

Step 1: Increase the power and energy to compensate for the loss in power/energy due to battery voltage drop across and internal impedance, battery charging/discharging efficiency and power electronics efficiency as per Figure 3.

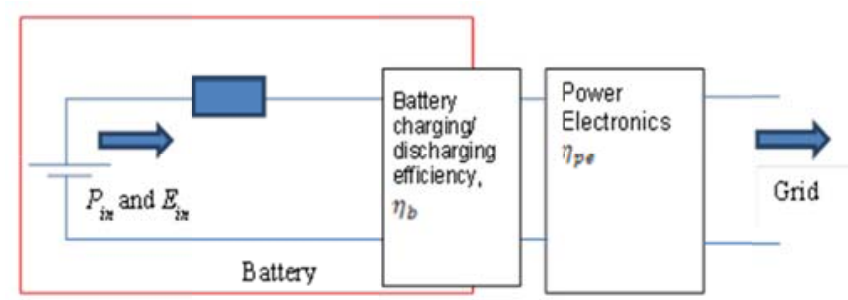

Fig 3: Battery model to compensate for efficiency
The minimum size of the battery, $P_{\text {in }}$ and $E_{\text {in }}$ minus the power/energy loss due to the internal impedance and multiplied by the battery charging/discharging efficiency and the power electronics efficiency gives the required energy and power to the grid. Working backwards allows the equations for power at the battery terminal to be derived:

$$
P_{i n}=I_{d c}^{2} Z_{b}+\frac{P_{b}}{\eta_{p e} \eta_{b}}
$$

Where $Z_{b}$ is the battery internal impedance and $I_{d c}$ is the total battery current calculated from

$$
I_{d c}=\frac{V_{o c} \pm \sqrt{V_{o c}^{2}-4 Z_{b} \frac{P_{b}}{\eta_{p e} \eta_{b}}}}{2 Z_{i b}}
$$

$\mathrm{I}_{\mathrm{dc}}$ is the solution to a quadratic because the dc bus terminal voltage is not known. However the battery open circuit voltage is normally known $\left(\mathrm{V}_{\mathrm{oc}}\right)$. This calculation may be complicated by the series and parallel combinations of cells. In which case individual cell power loss needs to be calculated and summed to give the total power loss. The total power provided by the battery can also be calculated from:

$$
P_{\text {in }}=I_{d c} V_{o c}
$$

The minimum energy required without the other factors can be found from scaling (ie whatever the power is scaled by, the energy needs to be scaled by too):

$$
E_{\text {in }}=E_{d c} x \frac{P_{i n}}{P_{d c}}
$$

Step 2: Take into account the Load Growth Factor $\left(F_{L G}\right)$ and Meshing Factor $\left(F_{S M}\right)$. The total battery power from (3) is multiplied by the load growth factor (estimated load growth at the substation as a pu increase in load with time), and the meshing factor (the proportion of the energy which would help with asset rating reduction if the network were meshed found from load flow analysis).

Step 3: From the data available determine if an additional, Life Span factor $\left(F_{L S}\right)$ is needed. This can be done a number of ways, but information on battery life cycle is needed from the manufacturer. Typically a curve of depth of discharge against number of life cycles is provided. One method of using this data is to plot the manufacturer's data as depth of discharge equivalent (DoDCE) against depth of discharge (where DoDCE is equal to depth of discharge multiplied by the number of life cycles at this point). Typically this should be close to a straight line where the DoDCE is close to a fixed value equal to the number of cycles at full DoD times the DoD [10].The lower the depth of discharge, the greater the number of cycles, and therefore the longer the life.

To calculate if the battery size needs to be increased to deal with life cycle issues, the expected lifecycle of the battery 
needs to be checked against the proposed charge/discharge cycling. to take into account the life cycle issues. Using the DoDCE method; the DoDCE is divided by the total number of cycles that the battery will undertake during its life (set to the number of discharges per year $\left(\mathrm{N}_{\mathrm{cy}}\right)$ times the expected life span of the battery $\left(\mathrm{N}_{\mathrm{y}}\right)$ ) this allows the maximum depth of discharge that can be used to meet the number of charging cycles to be calculated $\left(\mathrm{DoD}_{\mathrm{m}}\right)$. (If DoDCE is not a straight line then a look up table may be used in place of this or the method published in ref[11]).

$$
D o D_{m}=\frac{D o D C E}{N_{c y} x N_{y}}
$$

If this comes out to be greater than 100 then it means the battery has sufficient lifecycle available to meet the specified number of years operation at $100 \%$ DoD without needing to add an additional life span factor $\mathrm{F}_{\mathrm{LS}}$. If the number comes out less than 100 , say 50 this means the battery size has to be doubled (1/0.5) in order to ensure the battery is only discharged to $50 \%$ DoD to meet the life cycle. The $\mathrm{F}_{\mathrm{LS}}$ is therefore calculated as:

$$
F_{L S}=\frac{100}{D o D_{m}}=\frac{100 x N_{c y} x N_{y}}{D o D C E}
$$

This is only an approximation for sizing the battery based on the worst case analysis and the actual loss of life needs to be re-calculated after location and operating strategy are determined by the network operator.

Step 4: To deal with capacity fade, an intermediate energy is required, this is the value of energy that should remain after the specified number of years operation once the capacity has faded and is equal to

$$
E=E_{d c} x \frac{P_{i n}}{P_{d c}} x F_{L G}^{N_{y}} x F_{S M} x F_{L S}
$$

The capacity fade factor $\mathrm{F}_{\mathrm{CF}}$ is then found by considering capacity fade to be a function of Whr processed (as a pu of battery energy rating) [12,13] and can be found from the a combination of manufacturers data (to obtain a rate of capacity fade $\mathrm{R}_{\mathrm{CF}}$ ) and the quantity of Whr's the battery is likely to process each year over the minimum life span of the battery taking into account the increase in load using $F_{\mathrm{LG}}$ the load growth factor (ie the total throughput of energy is the energy per year $\left(E_{T}\right)$ times the load growth factor $\left(F_{L G}\right)$ over the total number of years).

$$
\begin{gathered}
C F=1-R_{C F}\left(\frac{\sum_{y=1}^{\text {No years }} E_{T} x\left(F_{L G}\right)^{y}}{E}\right) \\
F_{C F}=1-C F
\end{gathered}
$$

Step 5: The final total battery energy is therefore the energy at the end of life plus the energy lost due to capacity fade.

$$
E_{F}=E_{d c} x \frac{P_{i n}}{P_{d c}} x F_{L G}^{N_{y}} x F_{S M} x F_{L S}+E x F_{C F}
$$

This can be cross checked by multiplying this final energy by a capacity fade cross check

$$
1-R_{C F}\left(\frac{\sum_{y=1}^{\text {No years }} E_{T} x\left(F_{L G}\right)^{y}}{E_{F}}\right)
$$

And ending up with the energy, $E$, from equation (7).

The load factor $F_{L G}$ is provided by distribution network operator and is an estimate of load growth figure per year in pu. If the load growth is different in different years then instead of using $F_{L G}{ }^{N_{y}}$. The individual values for each year need multiplying together up to $\mathrm{N}_{\mathrm{y}}$. $\mathrm{F}_{\mathrm{LG} \text {,year1 }} \mathrm{F}_{\mathrm{LG}}$, year2 etc

The capacity fade and life span are also temperature dependent. To undertake a proper thermal analysis and determine the core battery temperature would require significant data and analysis. Approximations are possible and should these be necessary the equations can be derived at a later date. However, it should be noted that these are at best a poor approximation and will act to increase battery size further based on tenuous data.

\section{Operating strategy}

There are a number of different ways of operating the battery including; Manually, Forecast - Fixed schedule, Day ahead schedule, CT reading, Global scheme for multiple units, Single/multiple day strategies, Staggered starts and any combination of these . Within this paper three strategies will be looked at in more detail;

1. Fixed schedule (100\% battery power provided at set times)

2. CT reading (100\% battery power provided when an overload is registered)

3. Optimum strategy (The \% of battery power required to prevent the overload will be added when needed)

These strategies or modes of operation are determined from the overload magnitude and duration already calculated.

Mode 1 - Fixed schedule: The worst overload magnitude and duration already calculated will be used to set the on-off time for the battery, which will operate at these times every day. This means that battery is sometimes operating when not required.

Mode 2 - CT reading: The magnitude and duration of overload for each run period will be used to determine if the battery should be on or off. This way the battery is only ever on when needed but is not necessarily on at the optimum value. There is assumed to be one CT per radial feeder located to pick up the overload location. The battery would not be expected to monitor other feeders as it is unlikely that this would affect the need for reinforcement on a different feeder. 
Mode 3 - The magnitude and duration of the overload are used to directly match the battery output so that the battery is run with the minimum energy throughput to maximise life span.

\section{Calculation of loss of life, capacity fade and battery losses}

Once a battery size has been determined and the best location and operating strategy are realised. It is necessary to calculate the estimated loss of life and capacity fade from an operational perspective (as opposed to the estimated variables used for sizing the battery). This entails looking in more detail at each time the battery is discharged (assuming that charging happens as per manufacturer's instructions and the battery is charged and discharged to the same value each day).

Within the FALCON project, There are 18 different test days each of 48 half hour periods defined. These need to be collected together into types so that the number of days of each type is known. The kWhs for each day are calculated and the capacity fade can then be determined from:

$$
\text { Capacity fade }=1-R_{C F}\left(\frac{\sum_{y=1}^{\text {No years }} \sum_{d=1}^{18} n_{d} E_{d} x\left(F_{L G}\right)^{y}}{E_{\text {rated }}}\right)
$$

where $E_{\text {rated }}$ is the final size of the battery, $n_{d}$ is the number of similar days to that calculated, $E_{d}$ is the energy used in that day and, where not already included in the analysis, the load growth needs to be accounted for. The value for $E_{d}$ is the sum of the energy used in discharge each cycle $\left(E_{c}\right)$ over the period of the day being considered where $E_{c}$ equals energy from network operator when the appropriate load growth factor is applied to the loads.

$$
E_{d}=\sum_{c=1}^{\text {No cycles }} E_{c}
$$

The loss of life is calculated by summing up the DoDCE used over the period of study. This can be done by calculating the DoD and multiplying by the number of times this DoD has occurred and then summing over the period and subtracting from what is available.

$$
D o D C E_{\text {remaining }}=D o D C E-\sum_{y=1}^{\text {No years }} \sum_{d=1}^{18} \frac{n_{d} E_{d}}{E_{\text {rated }}}
$$

Where $n_{c}$ is the number of cycles in a day (expected to be 1) and $E_{c}$ is the $\mathrm{kWh}$ rating of that cycle. If there is only 1 cycle in the day then this is equal to $E_{d}$. The ratio of $E_{c}$ to $E_{\text {rated }}$ is the DoD. Note: load growth factor is taken into account when calculating $\mathrm{E}_{\mathrm{c}}$ for each year.

\section{Case study}

The proposed method is applied to project FALCON energy storage trial feeder within Milton Keynes Central area as Figure 4, where the energy storage trial sites are marked by circles.

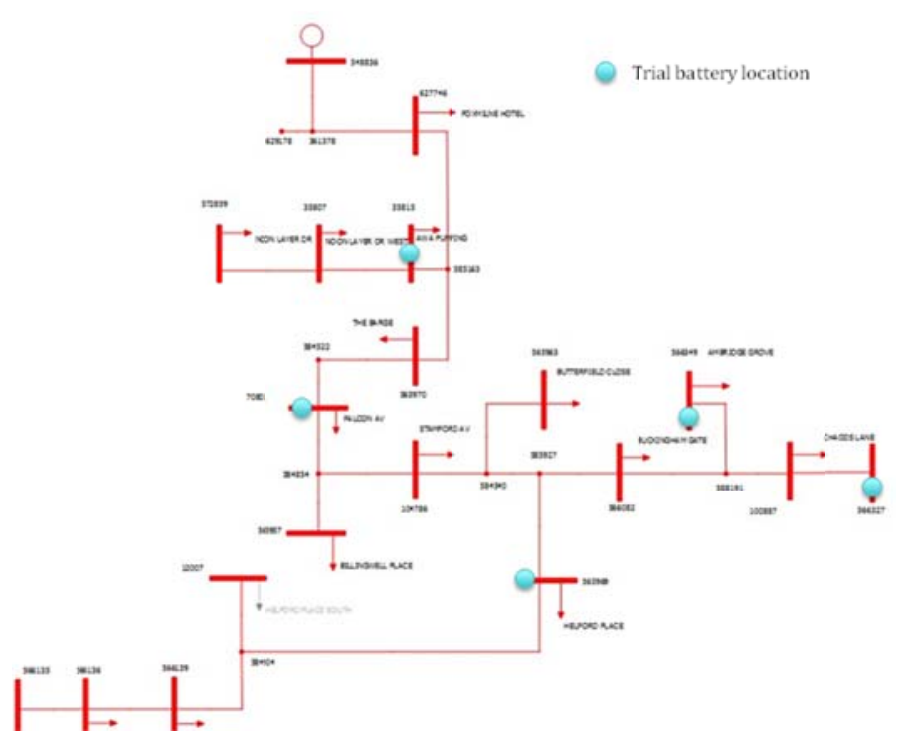

Fig 4: Energy storage trial feeder of project FALCON

The modelled loading in the network was increased until one of the assets went out of limits. This heavily loaded network was then modelled with a year on year load increases over a 5 year period. The three battery operation strategies above were adopted and the capacity fade and life time implications were determined through simulation for these cases.

The base case scenario (year 0) was determined by increasing all the substation loads until a cable rating was reached. In this base case, the loads were $\mathbb{1} .66$ times of the original load (Measured current from the DNO). Scenarios for the 5 years subsequent to this were calculated using load flow analysis with a $1 \%$ load growth per year.

In the following table, the current needed to compensate for the extra load growth and bring the overload back down to the static rating of the line, $I_{c}$ is found from:

$$
I_{c}=1.66 I_{b}\left(F_{L G y}-F_{L G b}\right)
$$

where, $F_{L G y}$ is the load growth factors at year $\mathrm{y}$ and $\mathrm{F}_{\mathrm{LGb}}$ equals 1 (starting point). For example, after two years the total load growth from the base year is 1.0201 and 6.9A (or $125 \mathrm{~kW}$ ) current compensation is needed to bring the line back down to rated value (This peak value occurs late at night and it is likely to be when an outage has occurred on an adjacent section of network and is being back fed). At three years there are additional overloads due to increasing load, and these are more in keeping with the traditional peak load scenario in February. After 5 years, $317 \mathrm{~kW}$ of battery size is needed to ensure no overloads on the network. Therefore, in this scenario, a battery size of say $350 \mathrm{~kW}$ would be needed (discharging at up to $90 \%$ DOD) to meet the load growth. These DOD values are listed in Table and can be used to estimate the battery lifetime. 


\begin{tabular}{|c|c|c|c|c|c|}
\hline$Y$ & $F_{L G y}$ & $\begin{array}{l}\text { Time of } \\
\text { overload }\end{array}$ & $\begin{array}{l}\text { kW to } \\
\text { compen } \\
\text { sate }\end{array}$ & $\begin{array}{l}\text { Battery } \\
k W\end{array}$ & $\begin{array}{l}\text { DoD with } \\
350 \mathrm{~kW} \\
\text { battery }\end{array}$ \\
\hline \multirow{2}{*}{1} & \multirow{2}{*}{1.01} & 23/05 22:00 & 62.19 & 70 & 0.2 \\
\hline & & 20/06 22:00 & 62.19 & 70 & 0.2 \\
\hline \multirow{2}{*}{2} & \multirow{2}{*}{1.02} & 23/05 22:00 & 125.29 & 140 & 0.4 \\
\hline & & 20/06 22:00 & 125.29 & 140 & 0.4 \\
\hline \multirow{4}{*}{3} & \multirow{4}{*}{1.03} & $05 / 02$ 18:00 & 69.40 & 70 & 0.2 \\
\hline & & 05/02 18:30 & 69.40 & 70 & 0.2 \\
\hline & & 23/05 22:00 & 188.68 & 210 & 0.6 \\
\hline & & 20/06 22:00 & 188.68 & 210 & 0.6 \\
\hline \multirow{8}{*}{4} & \multirow{8}{*}{1.04} & 05/02 18:00 & 139.11 & 140 & 0.4 \\
\hline & & 05/02 18:30 & 139.11 & 140 & 0.4 \\
\hline & & 23/05 21:30 & 62.79 & 105 & 0.3 \\
\hline & & 23/05 22:00 & 252.68 & 280 & 0.8 \\
\hline & & 24/05 22:00 & 62.794 & 105 & 0.3 \\
\hline & & 20/06 21:30 & 62.794 & 105 & 0.3 \\
\hline & & 20/06 22:00 & 252.68 & 280 & 0.8 \\
\hline & & 21/06 22:00 & 62.79 & 105 & 0.3 \\
\hline \multirow{8}{*}{5} & \multirow{8}{*}{1.05} & $05 / 02$ 18:00 & 209.71 & 210 & 0.6 \\
\hline & & 05/02 18:30 & 209.71 & 210 & 0.6 \\
\hline & & 23/05 21:30 & 125.89 & 175 & 0.5 \\
\hline & & 23/05 22:00 & 317.28 & 320 & 0.9 \\
\hline & & 24/05 22:00 & 125.89 & 175 & 0.5 \\
\hline & & 20/06 21:30 & 125.89 & 175 & 0.5 \\
\hline & & 20/06 22:00 & 317.28 & 320 & 0.9 \\
\hline & & 21/06 22:00 & 125.89 & 175 & 0.5 \\
\hline
\end{tabular}

Table 1: Loading scenarios with 1\% load growth over 5 years from maximum static limit

Note: The FALCON trial battery is a lead acid battery with a low life span at $100 \%$ DoD. According to the parameters from the manufacturer, the cycle life is 4500 cycles. This can be approximated to a DoDCE of 450,000. The combined battery/inverter efficiency is approximately $85 \%$

Fixed schedule (100\% battery power provided at set times) With the fixed schedule, the set times for discharging are fixed. Here, the battery will discharge two hours from 22:00 over an assummed two week period in the first 2 years (to meet the requirements for back feeding a neighbouring network). In the last 3 years, the battery will discharge during two time intervals, at 18:00-19:00 (every day, as representative of normal peak load) and 21:30-22:30 (over the same two week back-feed cycle). In each cycle, the battery will charge and discharge 2 hours to $100 \%$ DoD. The details for DoDCE, Cycles and Operation hours during the 5 year time period are shown in the Table. The DoDCE is based on a battery that fades, hence, as the battery fades the DoDCE equivalent for the same DoD increases because the capacity fade means the new rated capacity $\mathrm{E}_{\text {rated }}$ of the battery has reduced.

\begin{tabular}{|c|c|c|c|c|c|c|}
\hline$\underset{\nu}{\tilde{\Xi}}$ & $\begin{array}{l}\stackrel{\mathscr{U}}{\tilde{D}} \\
\stackrel{0}{0}\end{array}$ & 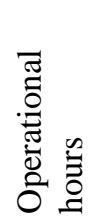 & 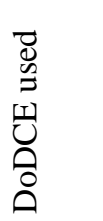 & 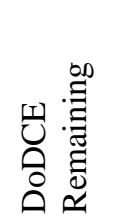 & 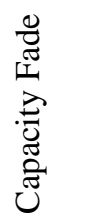 & 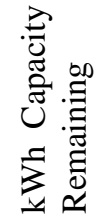 \\
\hline 1 & 14 & 56 & 1400 & 448600 & $1 \%$ & 696 \\
\hline 2 & 14 & 56 & 1408 & 447192 & $1 \%$ & 692 \\
\hline 3 & 379 & 1516 & 38338 & 408853 & $15 \%$ & 586 \\
\hline 4 & 379 & 1516 & 45280 & 363673 & $! 8 \%$ & 480 \\
\hline 5 & 379 & 1516 & 55271 & 308310 & $22 \%$ & 373 \\
\hline
\end{tabular}

Table 2: Battery operating schedule on fixed timing

On a fixed schedule, the battery capacity fades quickly when it is in daily use. By the time the battery reaches the $4^{\text {th }}$ year of operation, the battery would no longer be able to meet the discharge requirements necessary for the circuit to remain within the thermal limit. In fact, in order to size the battery to ensure 5 years of operation, approximately $800 \mathrm{kWh}$ of battery would be required at start of life.

CT reading (100\% battery power provided when an overload is registered): The set times for discharging are flexible. The batteries will operate only over the several days when the current exceeds the threshold. 100\% DOD is adopted in these operational days. According to the measured currents, the battery will discharge two hours from 22:00 in the first 2 years. In the last 3 years, the battery will discharge during two time intervals, at 18:00-19:00 and 21:30-22:30. In each cycle, the battery will charge and discharge 2 hours. Therefore, the operation hours for each cycle should be 4 hours. The details for DoDCE, Cycles and Operation hours during the 5 year time period are shown in table 3 . Using this CT reading strategy, the batteries do not operate every day, but they will discharge thoroughly in the operation days. As for fixed scheduling operation, the batteries will begin to discharge with $100 \%$ DOD when loads exceed the thermal limit. With the low usage the battery fade would be significantly slower than on a fixed schedule and therefore the battery would meet the $640 \mathrm{kWh}$ requirements of the $5^{\text {th }}$ year of operation. As the load increases over subsequent years of operation the battery capacity would start to fade more quickly.

Optimum strategy (The \% of battery power required to prevent the overload will be added when needed). The optimum strategy makes use of the magnitude and duration of the overload to match the battery output, so that the batteries run with the minimum energy throughput to maximise life span. Therefore, both the set times and the DOD are variable according to the overload power. Since the battery discharge power varies with the load curve, the DOD should be calculated over each 30 minute period and summed over the 
overload duration. With variable discharge power and time setting, the optimum strategy can minimise the capacity fade and maximise life span. The details are listed in table 4 . With an optimum strategy, very little loss of life is calculable. However, the peak loads are rather scarce in the studied scenarios and the control will be more complex to implement..

\begin{tabular}{|c|c|c|c|c|c|c|}
\hline$\stackrel{\Xi}{\beth}$ & $\frac{\mathscr{Q}}{\tilde{U}}$ & 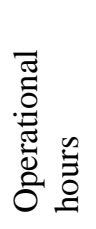 & 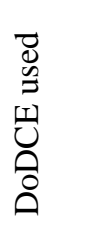 & 我茵 & 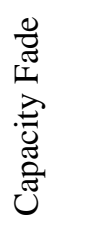 & 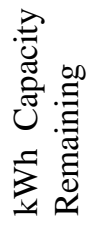 \\
\hline 1 & 2 & 8 & 200 & 449800 & $\sim 0$ & 699.4 \\
\hline 2 & 2 & 8 & $\sim 200$ & 449600 & $\sim 0$ & 698.8 \\
\hline 3 & 3 & 12 & $\sim 300$ & 449300 & $\sim 0$ & 697.8 \\
\hline 4 & 5 & 20 & 501 & 448800 & $0.2 \%$ & 696.4 \\
\hline 5 & 5 & 20 & 503 & 448300 & $0.2 \%$ & 695 \\
\hline
\end{tabular}

Table 1: Battery operating schedule on CT reading

\begin{tabular}{|c|c|c|c|c|c|c|}
\hline$\stackrel{\tilde{D}}{\partial}$ & $\frac{\mathscr{e}}{\stackrel{d}{u}}$ & 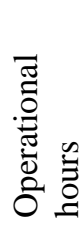 & 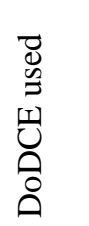 & 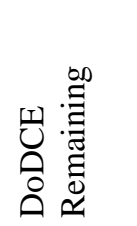 & 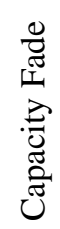 & 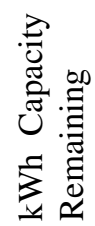 \\
\hline 1 & 0.09 & 2 & 10 & 449990 & $\sim 0$ & 700 \\
\hline 2 & 0.09 & 2 & $\sim 30$ & 4499970 & $\sim 0$ & 700 \\
\hline 3 & 0.33 & 4 & $\sim 70$ & 4499930 & $\sim 0$ & 700 \\
\hline 4 & 0.74 & 8 & $\sim 160$ & 449840 & $\sim 0$ & 700 \\
\hline 5 & 1.11 & 8 & $\sim 290$ & 449710 & $\sim 0$ & 700 \\
\hline
\end{tabular}

Table 4: Battery operating schedule on optimum discharge

\section{Conclusion}

It is important to understand capacity fade and battery degradation on energy storage. This is because the life span of the battery is dependent on how much the battery is discharged. Modelling indicates that the operation strategy is of great importance to capacity fade and life time and that the difference in modelled battery sizing could be as much as 2 times less if a flexible strategy rather than a fixed charging/discharging strategy were used. It is important to understand and validate the loss of life and capacity of the trial batteries as far as possible so that the implications on initial battery sizing can be used with confidence. To help with this, the FALCON trial batteries will be operated under different operating schedules and the effect on life span and capacity fade will be analysed.

\section{Acknowledgements}

The authors would like to acknowledge the assistance of WPD, TNEI and CGI who are partner organisations under the LCNF project FALCON.

\section{References}

[1] Yasser Moustafa, Atwa, E. F. El-Saadany, , “Optimal Allocation of ESS in Distribution Systems With a High Penetration of Wind Energy", IEEE TRANS ON POWER SYSTEMS, VOL. 25, NO. 4, 2010 p1815

[2] Zhang Yingda, Liu Nian, Zhang Jianhua “Optimum Sizing of Non-grid-connected Wind Power System Incorporating Battery-exchange Stations”, 2012 IEEE ECCE AsiaJune 2-5, 2012, Harbin, China

[3] D.P. Jenkins J. Fletcher D. Kane "Lifetime prediction and sizing of lead-acid batteries for microgeneration storage applications”,IET Renewable Power Generation, April 2008 [4] Ajai Gupta, R P Saini, and M P Sharma, "Hybrid Energy System Sizing Incorporating Battery Storage: An Analysis via Simulation Calculation” 2009 Third International Conference on Power Systems, Kharagpur, INDIA December 27-29

[5] Rau, Taylor "A central inventory of storage and other technologies to defer distribution upgrades - optimisation and economics” IEEE Trans on Power Delivery, Vol. 13, No. 1

[6] T. Logenthiran, Dipti Srinivasan "Intelligent Management of Distributed Storage Elements in a Smart Grid” IEEE PEDS 2011, Singapore, 5 - 8 December 2011January 1998

[7] "Online Parameterization of Lumped Thermal Dynamics in Cylindrical Lithium Ion Batteries for Core Temperature Estimation and Health Monitoring" Lin, X.; Perez, H. E.; Siegel, J. B.; Stefanopoulou, A. G.; Li, Y.; Anderson, R. D.; Ding, Y. Castanier, M. P. IEEE Trans.Control Systems Technology, , Issue: 992012 , Page(s): 1

[8] Christophersen, J.P.; Motloch, C.G.; Ho, C.D.; Battaglia, V.S.; Morrison, J.L.; Fenton, R.C.; Duong, T.Q. "Lumped parameter modeling as a predictive tool for a battery status monitor” VTC 2003, IEEE 58th Page(s): 3257 - 3261 Vol.5 [9] Lin Cheng; Chen Ke; Sun Fengchun; Tang Peng; Zhao Hongwei, "Research on thermo-physical properties identification and thermal analysis of EV Li-ion battery”, VPPC '09. IEEE, Page(s): 1643 - 1648

[10] JD Dogger, B Roossien, and FD J Nieuwenhout "Characterization of Li-Ion Batteries for Intelligent Management of Distributed Grid-Connected Storage” Energy Conversion, IEEE Trans on Vol 26,No.12011 ,pp: 256 - 263

[11] Drouilhet S., Johnson B.L.: 'A battery life prediction method for hybrid power applications'. Proc. 35th AIAAAerospace USA,January 1997

[12] Peterson, S.B., Apt, J, Whitacre J.F, "Lithium-ion battery cell degradation resulting from realistic vehicle and vehicle-to-grid utilization”, Journal of Power Sources, Elsevier, 2009, pp2385-2392

[13] Haran, B.S.; Ramadass, P.; White, R.E.; Popov, B.N. "Capacity fade of Li-ion cells cycled at different temperatures" Battery Conference on Applications and Advances, 2002. The Seventeenth Annual pp 13 - 18 